\title{
Thyroid Function, Reverse Triiodothyronine, and Mortality in Critically Ill Clinical Patients
}

\author{
Carlos DG da Silveira ${ }^{1} \oplus$, Flávio PJ de Vasconcelos ${ }^{2} \odot$, Edmilson B Moura ${ }^{3} \odot$, Bruno TG da Silveira ${ }^{4}$, Flávio FP Amorim ${ }^{5} \odot$, \\ Lumie S Shintaku ${ }^{6}$, Rosália B de Santana ${ }^{7}$, Pedro LP Argotte $^{8} \odot$, Sheila F da Silva ${ }^{9}$, Marcelo de Oliveira Maia ${ }^{10}$, \\ Fabio F Amorim ${ }^{11} \odot$
}

\begin{abstract}
Background: To evaluate the association of thyroid hormones changes, including increased reverse triiodothyronine (rT3) level, with critically ill clinical patients' mortality.

Patients and methods: This study analyzed the observational data prospectively collected over 8 months (2018) in an adult intensive care unit (ICU) in Brasilia, Brazil. All consecutive ICU-admitted clinical patients were included. Thyroxine (T4), free thyroxine (fT4), triiodothyronine (T3), free triiodothyronine (fT3), rT3, and thyroid-stimulating hormone (TSH) were collected within 48 hours of ICU admission. Patients with hypothyroidism or hyperthyroidism who were previously diagnosed were excluded.

Results: Of 353 included patients, age was $68.5 \pm 19.0$ years, sequential organ failure assessment (SOFA) score was $3.3 \pm 2.9$, and Acute Physiology and Chronic Health Evaluation II (APACHE II) was $17.1 \pm 7.9$. ICU mortality was $17.6 \%(n=62)$. Non-survivor patients had a higher incidence of increased rT3 (69.3 vs $59.2 \%, p=0.042)$, lower incidence of low T4 ( 4.8 vs $9.7 \%, p=0.045)$, and increased age $(75.2 \pm 16.3$ years vs $67.1 \pm 19.3$ years, $p=0.001)$, SOFA $(3.0 \pm 0.4$ vs $2.8 \pm 2.6, p<0.001)$, and APACHE II $(23.5 \pm 7.5$ vs $15.7 \pm 7.2, p<0.001)$. Alterations in other thyroid hormones did not show association with mortality. Increased rT3 [odds ratio (OR): $2.436 ; 95 \%$ confidence interval (Cl): $1.023-5.800 ; p=0.020$ ] and APACHE II (OR: $1.083,95 \%$ Cl: 1.012-1.158; $p=0.044$ ) were associated with ICU mortality in the multivariate analysis.

Conclusion: Increased rT3 was independently associated with increased ICU mortality. In contrast, other thyroid hormone alterations did not show an association with mortality. Determining rT3 levels may be a helpful test to identify an increased risk for ICU mortality in clinical patients. Keywords: Intensive care units, Mortality, Reverse, Thyroid gland, Thyroid hormones, Triiodothyronine.

Indian Journal of Critical Care Medicine (2021): 10.5005/jp-journals-10071-24001
\end{abstract}

\section{INTRODUCTION}

Changes in serum thyroid hormones have been described in acute critically ill patients without preexisting thyroid gland disease. ${ }^{1-4}$ Among these changes, the classic euthyroid sick syndrome (ESS) is characterized by low triiodothyronine (T3), increased reverse T3 (rT3), and normal thyroid-stimulating hormone (TSH) without previous hypothalamic-pituitary dysfunction or preexisting thyroid gland disease. ${ }^{5}$ After recovery from the non-thyroid disease that triggered the ESS, the thyroid function is entirely reversible. ${ }^{6}$ In later stages, central hypothyroidism may occur, characterized by a decrease in T3, thyroxine (T4), and TSH. ${ }^{7}$ Diversely, in early stages, an increase in rT3, with normal levels of T3 and TSH, may be observed due to a reduction in the peripheral T4 to T3 conversion. ${ }^{5}$ The possible mechanisms associated with these changes in the thyroid hormones can be alterations in the release of TSH, the activity of iodothyronine deiodinase, the bind of thyroid hormone to plasma proteins, the transport of the thyroid hormone to peripheral tissues, and the activity of the nuclear thyroid hormone receptor. ${ }^{5}$

The ESS can be observed in 44 to $70 \%$ of critically ill patients. ${ }^{8}$ Although it usually occurs in patients with acute diseases, it can also be seen in chronic diseases, such as chronic kidney disease and diabetes mellitus. ${ }^{2-4,9-11}$ It should not be seen as a disconnected physiopathological event but as an integrated systemic reaction to illness connecting the endocrine and immune systems. ${ }^{12}$

Adverse events, such as fasting, may cause a rapid decline in T3 and free T3 (fT3) associated with a decrease in the basal metabolic rate, representing an adaptive response to save calories
1,10,11Programa de Pós-Graduação em Ciências da Saúde, Escola Superior de Ciências da Saúde, Brasília, Distrito Federal, Brazil

${ }^{2}$ Escola Superior de Ciências da Saúde, Brasília, Distrito Federal, Brazil

${ }^{3-8}$ School of Medicine, Escola Superior de Ciências da Saúde, Brasília, Distrito Federal, Brazil

${ }^{9}$ Adult Intensive Care Unit, Hospital Santa Luzia - Rede D'Or São Luiz, Brasilia, Distrito Federal, Brazil

Corresponding Author: Fabio F Amorim, Programa de Pós-Graduação em Ciências da Saúde, Escola Superior de Ciências da Saúde, Brasília, Distrito Federal, Brazil, Phone: +61999773516, e-mail: ffamorim@ gmail.com

How to cite this article: da Silveira CDG, de Vasconcelos FPJ, Moura EB, da Silveira BTG, Amorim FFP, Shintaku LS, et al. Thyroid Function, Reverse Triiodothyronine, and Mortality in Critically III Clinical Patients. Indian J Crit Care Med 2021;25(10):1161-1166.

Source of support: Nil

Conflict of interest: None

and protein..$^{6-13}$ Despite the potential beneficial effects, previous studies had shown an association between ESS and unfavorable outcomes in several conditions. ${ }^{7,9,11,14-17}$ In one study, low levels of T3 in critical patients were associated with overall and cardiac mortality. ${ }^{15}$ Furthermore, the drop in T4 levels below $4 \mu \mathrm{g} / \mathrm{dL}$ has been associated with increased intensive care unit (ICU) mortality, reaching $80 \%$ when T4 levels fall under $2 \mu \mathrm{g} / \mathrm{dL}^{15-17}$ 
Although the association of rT3 elevation and unfavorable outcomes had been described in several clinical conditions, such as end-stage chronic kidney disease, ${ }^{13}$ acute myocardial infarction (AMI) ${ }_{1}^{14}$ hepatic diseases, ${ }^{8}$ and older adults, ${ }^{9}$ few studies assessed the rT3 elevation, which is observed in the early stage of ESS. ${ }^{18}$ Among these, one study, analyzing patients who required an ICU length of stay (ICU-LOS) of at least 5 days showed that rT3 levels within 48 hours of admission were higher among non-survivors. ${ }^{18}$

Since the consequences of thyroid function alterations in critically ill patients remain poorly understood, particularly elevation of rT3, this study intended to analyze the thyroid hormone changes, especially the increase in rT3 level, association with ICU mortality.

\section{Materials and Methods}

Our study analyzed the observational data prospectively collected from March 2018 to October 2018 in an adult ICU with 40-bed of a tertiary hospital in Brasilia, Brazil. The study included all nonsurgical patients older than 18 years, consecutively admitted in the ICU during the study period. Patients with previously diagnosed thyroid disease or using thyroid hormone before hospital admission, patients who were transferred to an ICU of other hospitals, and pregnant patients were excluded. Some of these data have been previously reported in abstract form. 19,20

Patients' general characteristics and blood samples were collected within 24 hours of ICU admission: Demographic data, body mass index, the reason for hospitalization, comorbidities, previous use of corticosteroids, Acute Physiology and Chronic Health Evaluation II (APACHE II), Simplified Acute Physiology Score II, blood count, electrolytes, lactate, and C-reactive protein (CRP). We collected T4, free T4 (fT4), T3, rT3, fT3, and TSH within 48 hours of ICU admission in the morning. Blood was drawn from nonheparinized central lines. Competitive chemiluminescent immunoassays were used for TSH, $\mathrm{T} 4$, $\mathrm{TT} 4, \mathrm{~T} 3$, and $\mathrm{fT} 3$ measurements. Liquid chromatography and mass spectrometry in tandem were used for rT3 measurement. Mortality was assessed until discharge from the ICU.

Kolmogorov-Smirnov test with Liliefors correction was used for the normality distribution test. Quantitative data are expressed as mean \pm standard deviation (SD) or median and 25 to $75 \%$ interquartile range (25-75th IQ). Categorical variables are expressed as numbers and percentages (\%). According to the outcome to be analyzed (dependent variable), the research subjects were grouped according to the studied independent variable. When appropriate, Student's $t$-test or Mann-Whitney U-test was used to compare quantitative variables. For categorical variables, contingency tables and Pearson's Chi-square test $\left(x^{2}\right)$ or Fisher's exact test were used as appropriate. To assess the independent factors associated with ICU mortality, noncollinear variables associated with ICU mortality with a $p$-value $<0.20$ in the univariate analysis were assessed by binary logistic regression analysis using the stepwise method. Data were analyzed by using the IBM Statistical Package for Social Sciences (SPSS) software program, version 20.0 (SPSS, Chicago, Illinois, USA). The statistical significance level was defined as a two-sided $p$-value $\leq 0.05$. The study was approved by the Local Ethics Committee.

\section{RESULTS}

During the study period, 498 medical patients were admitted to ICU. Of these, 145 patients were excluded (130 with a previous thyroid disease diagnosis or in use of thyroid hormone before hospitalization, 10 pregnant women, and 5 transfers to the therapy unit from another hospital), which corresponds to $29.1 \%$ of total hospitalizations in ICU. Thus, the study included 353 patients.

Table 1 shows the demographic characteristics, laboratory tests, and outcomes. The age was $68.5 \pm 19.0$ years, APACHE II was $17.1 \pm 7.9$, SOFA was $3.3 \pm 2.9$, and $59.2 \%$ were female ( $n=209$ ). Of these, $14.3 \%$ used corticosteroids previously during hospitalization $(n=37)$. The main reasons for hospitalization were the involvement of the respiratory system $(n=115 ; 32.6 \%)$, followed by the neurological system $(n=52 ; 14.7 \%)$ and digestive system ( $n=39 ; 11 \%)$. Concerning comorbidities, $56.6 \%$ had systemic arterial hypertension ( $n=197), 25.5 \%$ diabetes mellitus ( $n=90), 10.5 \%$ chronic obstructive pulmonary disease $(n=37)$, and $4.3 \%$ chronic kidney disease $(n=15)$. Low T3 was observed in $11.6 \%(n=41)$, low fT3 in $39.7 \%(n=140)$, low T4 in $12.5 \%(n=44)$, low fT4 in $8.8 \%$ $(n=31)$, high rT3 in $71.1 \%(n=216)$, and low TSH in $13.3 \%(n=47)$.

Table 1: Demographic characteristics, laboratory tests, and outcomes

\begin{tabular}{|c|c|}
\hline & Value \\
\hline Age, years, mean (SD) & $68.5(19.0)$ \\
\hline Female gender, $n(\%)$ & $209(59.2)$ \\
\hline APACHE II, mean (SD) & $17.1(7.9)$ \\
\hline SOFA, mean (SD) & $3.3(2.9)$ \\
\hline $\begin{array}{l}\text { Reason for hospitalization, } n(\%) \\
\text { Respiratory } \\
\text { Neurological } \\
\text { Digestive } \\
\text { Hematological } \\
\text { Cardiovascular } \\
\text { Others }\end{array}$ & $\begin{array}{r}115(32.6) \\
52(14.7) \\
39(11.0) \\
39(11.0) \\
17(4.8) \\
91(25.8)\end{array}$ \\
\hline $\begin{array}{l}\text { Comorbidity, } n(\%) \\
\text { Systemic arterial hypertension } \\
\text { Diabetes mellitus } \\
\text { COPD } \\
\text { Chronic kidney disease }\end{array}$ & $\begin{array}{c}197(56.6) \\
90(25.5) \\
37(10.5) \\
15(4.3)\end{array}$ \\
\hline Previous use of corticosteroids, $n$ (\%) & $37(14.3)$ \\
\hline High rT3, $n(\%)^{\mathrm{a}}$ & $216(71.1)$ \\
\hline Low T3, $n(\%)$ & $41(11.6)$ \\
\hline Low fT3, $n(\%)$ & $140(39.7)$ \\
\hline Low T4, $n(\%)$ & $44(12.5)$ \\
\hline Low fT4, $n(\%)$ & $31(8.8)$ \\
\hline Low TSH, $n$ (\%) & $47(13.3)$ \\
\hline High arterial lactate, $n(\%)$ & $29(46.6)$ \\
\hline High CRP, $n(\%)$ & $257(73.3)$ \\
\hline Hyponatremia, $n(\%)$ & $127(36.0)$ \\
\hline Hypernatremia, $n(\%)$ & $17(4.8)$ \\
\hline Hypokalemia, $n$ (\%) & $78(22.1)$ \\
\hline Hyperkalemia, $n(\%)$ & $16(4.5)$ \\
\hline Hematocrit <28\%, $n$ (\%) & $103(29.2)$ \\
\hline LOS in ICU, days, median (IQ 25-75\%) & $4.0(3.0-8.0)$ \\
\hline Mortality in the ICU, $n(\%)$ & $62(17.6)$ \\
\hline \multicolumn{2}{|c|}{$\begin{array}{l}\text { APACHE II, acute physiology and chronic evaluation II; SOFA, sequential } \\
\text { organ failure assessment; COPD, chronic obstructive pulmonary disease; } \\
\text { T3, triiodothyronine; rT3, reverse T3; fT3, free triiodothyronine; T4, } \\
\text { tetraiodothyronine; fT4, free tetraiodothyronine; TSH, thyroid-stimulating } \\
\text { hormone; ICU, intensive care unit; SD, standard deviation; IQ25-75\%: inter- } \\
\text { quartile range } 25-75 \% \text {. }{ }^{\text {rTT3 }} \text { was dosed in } 304 \text { patients }\end{array}$} \\
\hline
\end{tabular}


Thyroid Function, rT3, and Mortality in ICU

Table 2: Univariate analysis of factors associated with ICU mortality

\begin{tabular}{|c|c|c|c|}
\hline Variable & Survivors $(n=291)$ & Non-survivors $(n=62)$ & $p$ value \\
\hline Age, years, mean (SD) & $67.1(19.3)$ & $75.2(16.3)$ & 0.001 \\
\hline Women gender, $n(\%)$ & $171(58.8)$ & $38(61.3)$ & 0.713 \\
\hline APACHE II, mean (SD) & $15.7(7.2)$ & $23.5(7.5)$ & $<0.001$ \\
\hline SOFA, mean (SD) & $2.8(2.6)$ & $3.0(0.4)$ & $<0.001$ \\
\hline \multicolumn{4}{|l|}{ Comorbidity, $n$ (\%) } \\
\hline Systemic arterial hypertension & $161(56.1)$ & $36(59.0)$ & 0.676 \\
\hline Diabetes mellitus & $7(11.3)$ & $30(10.3)$ & 0.819 \\
\hline COPD & $7(11.3)$ & $30(10.3)$ & 0.819 \\
\hline Chronic kidney disease & $10(3.5)$ & $5(8.2)$ & 0.104 \\
\hline Previous use of corticosteroids, $n$ (\%) & $30(14.0)$ & $7(15.9)$ & 0.736 \\
\hline High rT3, $n(\%)^{*}$ & $173(59.4)$ & $43(69.3)$ & 0.042 \\
\hline Low T3, $n(\%)$ & $36(12.4)$ & $5(8.1)$ & 0.337 \\
\hline Low fT3, $n(\%)$ & $120(41.2)$ & $20(32.3)$ & 0.189 \\
\hline Low T4, $n(\%)$ & $41(14.1)$ & $3(4.8)$ & 0.045 \\
\hline Low fT4, $n$ (\%) & $28(9.7)$ & $3(4.8)$ & 0.222 \\
\hline Low TSH, $n$ (\%) & $37(12.7)$ & $10(16.1)$ & 0.472 \\
\hline High arterial lactate, $n(\%)$ & $149(51.2)$ & $29(46.8)$ & 0.239 \\
\hline High CRP, $n(\%)$ & $208(71.7)$ & $49(79.0)$ & 0.239 \\
\hline Hyponatremia, $n(\%)$ & $104(35.7)$ & $23(37.1)$ & 0.840 \\
\hline Hypernatremia, $n(\%)$ & $14(4.8)$ & $3(4.8)$ & 0.993 \\
\hline Hypokalemia, $n(\%)$ & $65(22.3)$ & $13(21.0)$ & 0.814 \\
\hline Hyperkalemia, $n$ (\%) & $11(3.8)$ & $5(8.1)$ & 0.141 \\
\hline Hematocrit $<28 \%, n(\%)$ & $84(28.9)$ & $19(30.6)$ & 0.780 \\
\hline
\end{tabular}

Arterial lactate was increased in $46.8 \%$ of patients $(n=29)$, and CRP was increased in $73.3 \%(n=29)$.

Table 2 shows the univariate analysis of the variables associated with ICU mortality and lower incidence of low T4 levels (4.8 vs $9.7 \%, p=0.045)$. Non-survivor patients had a higher incidence of increased rT3 (69.3 vs $59.2 \%, p=0.042)$, reduced incidence of low T4 (4.8 vs 9.7\%, $p=0.045)$, increased age $(75.2 \pm 16.3$ years vs $67.1 \pm 19.3$ years, $p=0.001)$, SOFA $(3.0 \pm 0.4$ vs $2.8 \pm 2.6, p<0.001)$, and APACHE II $(23.5 \pm 7.5$ vs $15.7 \pm 7.2, p<0.001)$. Concerning other thyroid hormones (T3, fT3, fT4, and TSH), gender, comorbidities, and other laboratory tests evaluated, there was no statistically significant difference.

Table 3 shows the multivariate analysis of variables associated with ICU mortality, in which only high rT3 [odds ratio (OR): 2.436; 95\% confidence interval (CI): 1.023-5.800; $p=0.020$ ] and APACHE II (OR: 1.083; 95\% Cl: 1.012-1.158; $p=0.044$ ) showed an independent association. Low T4, SOFA, and age did not show a statistically significant difference.

Patients with elevated rT3 levels had longer ICU-LOS [4 (3-8) days vs $1(0-1)$ day, $p=0.014]$. Regarding the low T3 level, there was no statistically significant association with the ICULOS, $p=0.902$.

\section{Discussion}

Serious illnesses can affect the state of thyroid hormones, even in people with normal thyroid function. ${ }^{1-4}$ In our study, elevated rT3 collected within 48 hours of ICU admission was associated with ICU
Table 3: Multivariate analysis of factors associated with mortality in the ICU

\begin{tabular}{lcc}
\hline Variable & OR $(95 \% \mathrm{Cl})$ & pvalue \\
\hline Age & $1.002(0.995-1.041)$ & 0.129 \\
SOFA & $1.173(0.999-1.378)$ & 0.051 \\
APACHE II & $1.083(1.012-1.158)$ & 0.044 \\
Low T4 & $4.130(0.903-18.878)$ & 0.067 \\
High rT3 & $2.436(1.023-5.800)$ & 0.020 \\
\hline
\end{tabular}

T4, thyroxine; rt3, reverse triiodothyronine; APACHE II, acute physiologyand chronic evaluation II; SOFA, sequential organ failure assessment; OR, odds ratio; $95 \% \mathrm{Cl}, 95 \%$ confidence interval. HosmerLemeshow test $\mathrm{X}^{2}=11.083, \mathrm{DF}=8, p$-value $=0.197$

mortality. Notwithstanding, alterations in other thyroid hormone levels (T3, fT3, T4, fT4, and TSH) did not show an independent association with ICU mortality. Previous studies also correlated changes in thyroid hormones to worse prognosis in acute and critical illnesses and chronic diseases, such as heart failure, diabetes mellitus, and chronic kidney disease. However, most of these studies correlate ESS and the reduction in T3 and T4 with increased mortality, ${ }^{1,2,15,18,21}$ and few studies evaluated the association between isolated rT3 level and outcomes. $9,14,18,22$

Although the mechanisms for the elevation of rT3 remain uncertain, we can conceive that they are, at least in part, similar to those involved in $\mathrm{ESS}^{10}$ such as changes in the activity of 
iodothyronine deiodinase, the thyroid hormones transport to peripheral tissues, the thyroid hormone nuclear receptor activity, and the TSH and thyrotropin-releasing hormone secretions. ${ }^{2,10,23-25}$ One mechanism that can explain the isolated elevation of rT3 is a drop of its clearance in the liver that appears earlier, also leading to a fall in the fT3 level. ${ }^{9}$ The low half-life of rT3 (around 3 hours compared to 24 hours for T3) makes rT3 a sensitive and earliest marker for acute changes in thyroid hormones' metabolism. ${ }^{26-28}$

In AMI, there is a rapid decrease in serum concentrations of thyroid hormones. ${ }^{29-34}$ These changes in intensity were related to an increased rate of adverse clinical conditions and unfavorable outcomes. ${ }^{14,35,36}$ Kimur et al. ${ }^{37}$ showed that the drop of T3 was associated with left ventricular dysfunction, significant necrosis extension, and more intense proinflammatory and stress response in AMI. Other studies found that low T3 and increased rT3 were related to an increase in major cardiac events and could predict both short-term and long-term mortality. ${ }^{14,36}$ Friberg et al.., ${ }^{14}$ evaluating 385 patients with AMI, observed that patients with elevated rT3 had three times more mortality. Furthermore, the isolated elevation of rT3, but not the change in fT4, was associated with mortality in the first year of follow-up, suggesting the rT3 measurement may be a helpful and simple test to identify patients with increased risk for unfavorable outcomes. Although the mechanisms that could explain the correlation of elevation of rT3 with the worsening prognosis are not yet fully understood, the authors hypothesized the elevated rT3 might be associated with increased vascular resistance and reduced cardiac output, which can be especially harmful when combined with hemodynamic changes similar to heart failure related to AMI.

Forestier et al. ${ }^{9}$ showed the increased $\mathrm{rT3}$ was the only thyroid hormone change related to shorter survival in a study that included 440 independently living elderly, reaching a specificity to predict early death up to $98.5 \%$. On the contrary, a previous study performed by van den Beld et al. ${ }^{10}$ did not show an association between rT3 elevation and survival, also assessing a group of independently living elderly; however, the patients who met the diagnostic criteria for ESS or had an isolated rT3 increase or a rise in fT4 presented a reduced physical capacity. Comparing these two studies, the patients in the study carried out by van den Beld et al. ${ }^{10}$ had a better health state than the patients in the study by Forestier et al., ${ }^{9}$ since none of patients in the first study were under treatment due to inflammatory, infectious, or malignant diseases. These results suggest the isolated elevation of rT3 ("elevated rT3 syndrome") can be related to a catabolic state that precedes the typical ESS that may reflect more than a merely nutritional condition, but a low general health condition, finding that can also be applied to critically ill patients. ${ }^{9}$

A previous study showed that increased rT3 and low T3/rT3 ratio within the first 24 hours of ICU admission were associated with increased hospital mortality in patients who required an ICU stay of at least 5 days. Besides, on the fifth day after ICU admission, T4, T3, and TSH were highest in survivors. ${ }^{18,38}$ It was also observed that postmortem liver and skeletal muscle biopsies, serum levels of rT3 correlated with iodothyronine deiodinases' tissue activity, suggesting a significant role for deiodinases in the thyroid hormone changes. ${ }^{18,38-41} \mathrm{~A}$ Chinese study showed that ICU-patients with ESS were more likely to have the most unsatisfactory health state, and increased rT3 was related to severe disease states. ${ }^{20}$

Several factors may explain the association between increased rT3 and unfavorable outcomes in critically ill patients since the modifications in thyroid function are due to heterogeneous conditions. It is also speculated that rT3 has direct effects on mortality, but not yet completely clarified. In experimental animal studies, it was shown that rT3 might interact with the integrin avB3 reducing the oxidative stress induced by congenital hypothyroidism in the hippocampus of immature rats, ${ }^{42}$ whereas $r T 3$, through non-genomic mechanisms, can increase calcium uptake in Sertoli cells of immature rats ${ }^{43}$ and participate in the regulation of actin polymerization of neurons of the central nervous system. ${ }^{44}$ Besides, in addition to direct actions, rT3 may act as a competitive inhibitor disrupting T3 signaling that may correlate with unfavorable prognosis. $^{14}$

Our study has several limitations. First, our study is unicentric and observational, and the intrinsic limitations of this type of study limit the results' generalization. Second, it was performed in a single collection of thyroid hormones in the first 48 hour of admission to the ICU, which does not allow us to elucidate the pathophysiological events associated with the rT3 and the worse outcomes. Additional studies are required to corroborate our findings and assess the mechanisms associated with "elevated rT3 syndrome" to worse outcomes.

\section{Conclusion}

Our study showed that increased rT3 was independently associated with increased ICU mortality. In contrast, other thyroid hormone alterations did not show an association with mortality. Determining rT3 levels may be a helpful test to identify an increased risk for ICU mortality in clinical patients. Additional studies are necessary to evaluate how measuring $\mathrm{rT} 3$ adds prognostic information to existing conventional outcome risk stratification, such as SOFA.

\section{OrCID}

Carlos DG da Silveira 나 https://orcid.org/0000-0001-8504-6283

Flávio PJ de Vasconcelos @ https://orcid.org/0000-0001-5055-7067

Edmilson B Moura ㄴ. https://orcid.org/0000-0003-3344-8453

Bruno TG da Silveira 으 https://orcid.org/0000-0003-3314-8549

Flávio FP Amorim (1) https://orcid.org/0000-0003-2580-5545

Lumie S Shintaku (1) https://orcid.org/0000-0001-7410-3027

Rosália B de Santana @ ittps://orcid.org/0000-0002-7220-2774

Pedro LP Argotte (1) https://orcid.org/0000-0002-1326-0536

Sheila F da Silva 나 https://orcid.org/0000-0002-1924-6583

Marcelo de Oliveira Maia (ㄱ) https://orcid.org/0000-0002-7220-2774

Fabio F Amorim (1) https://orcid.org/0000-0003-0929-5733

\section{References}

1. Lee S, Farwell AP. Euthyroid sick syndrome. Compr Physiol 2016;6(2):1071-1080. DOI: 10.1002/cphy.c150017.

2. Van den Berghe G. Non-thyroidal illness in the ICU: a syndrome with different faces. Thyroid 2014;24(10):1456-1465. DOI: 10.1089/ thy.2014.0201.

3. Boelen A, Kwakkel J, Fliers E. Beyond low plasma T3: Local thyroid hormone metabolism during inflammation and infection. Endocr Rev 2011;32(5):670-693. DOI: 10.1210/er.2011-0007.

4. Farwell AP. Thyroid hormone therapy is not indicated in the majority of patients with the sick euthyroid syndrome. Endocr Pract Endocrinol 2008;14(9):1180-1187. DOI: 10.4158/EP.14.9.1180.

5. Chopra IJ, Chopra U, Smith SR, Reza M, Solomon DH. Reciprocal changes in serum concentrations of 3,3',5-triiodothyronine (T3) in systemic illnesses. J Clin Endocrinol Metab 1975;41(06):1043-1049. DOI: 10.1210/jcem-41-6-1043. 
6. Chopra IJ. Nonthyroidal illness syndrome or euthyroid sick syndrome? Endocr Pract 1996;2(1):45-52. DOI: 10.4158/EP.2.1.45.

7. Sorvillo F, Mazziotti G, Carbone A, Morisco F, Cioffi M, Rotondi M, et al. Increased serum reverse triiodothyronine levels at diagnosis of hepatocellular carcinoma in patients with compensated HCVrelated liver cirrhosis. Clin Endocrinol (Oxf) 2003;58(2):207-212. DOI: 10.1046/j.1365-2265.2003.01697.x.

8. Kaptein EM, Weiner JM, Robinson WJ, Wheeler WS, Nicoloff JT. Relationship of altered thyroid hormone indices to survival in nonthyroidal illnesses. Clin Endocrinol 1982;16(6):565-574. DOI: 10.1111/j.1365-2265.1982.tb03173.x.

9. Forestier E, Vinzio S, Sapin R, Schlienger JL, Goichot B. Increased reverse triiodothyronine is associated with shorter survival in independently-living elderly: the Alsanut study. Eur J Endocrinol 2009;160(2):207-214. DOI: 10.1530/EJE-08-0519.

10. van den Beld AW, Visser TJ, Feelders RA, Grobbee DE, Lamberts SW. Thyroid hormone concentrations, disease, physical function, and mortality in elderly men. J Clin Endocrinol Metab 2005;90(12):6403-6409. DOI: 10.1210/jc.2005-0872.

11. Horáček J, Dusilová Sulková S, Kubišová M, Safránek R, Malířová E, Kalousová $M$, et al. Thyroid hormone abnormalities in hemodialyzed patients: low triiodothyronine as well as high reverse triiodothyronine are associated with increased mortality. Physiol Res 2012;61(5): 495-501. DOI: 10.33549/physiolres.932321.

12. Haddady S, Farwell AP. Non-thyroidal illness and the management of thyroid disorders in the Intensive Care Unit. In: Irwin RS, Rippe JM, editors. Intensive Care Medicine, Philadelphia: Lippincott, Williams \& Wilkins; 2011. p. 1182-1194.

13. Welle SL, Campbell RG. Decrease in resting metabolic rate during rapid weight loss is reversed by low dose thyroid hormone treatment. Metabolism 1986;35(4):289-291. DOI: 10.1016/0026-0495(86)90142-3.

14. Friberg L, Drvota V, Bjelak AH, Eggertsen G, Ahnve S. Association between increased levels of reverse triiodothyronine and mortality after acute myocardial infarction. Am J Med 2001;111(9):699-703. DOI: 10.1016/s0002-9343(01)00980-9.

15. Maldonado LS, Murata GH, Hershman JM, Braunstein GD. Do thyroid function tests independently predict survival in the critically ill? Thyroid 1992;2(2):119-123. DOI: 10.1089/thy.1992.2.119.

16. Kaptein EM, Weiner JM, Robinson WJ, Wheeler WS, Nicoloff JT. Relationship of altered thyroid hormone indices to survival in nonthyroidal illnesses. Clin Endocrinol (Oxf) 1982;16(6):565-574. DOI: 10.1111/j.1365-2265.1982.tb03173.x.

17. Slag MF, Morley JE, Elson MK, Crowson TW, Nuttall FQ, Shafer RB. Hypothyroxinemia in critically ill patients as a predictor of high mortality. JAMA 1981;245(1):43-45. DOI: 10.1001/ jama.1981.03310260021020.

18. Peeters RP, Wouters PJ, van Toor H, Kaptein E, VisserTJ, Van den Berghe G. Serum 3,3',5'-triiodothyronine (rT3) and 3,5,3'-triiodothyronine/rT3 are prognostic markers in critically ill patients and are associated with postmortem tissue deiodinase activities. J Clin Endocrinol Metab 2005;90(8):4559-4565. DOI: 10.1210/jc.2005-0535.

19. Amorim FF, Silveira CDG, Shintaku LS, Argotte PLP, Silveira BTG, Amorim FFP, et al. Euthyroid sick syndrome and mortality in clinical critical ill patients. Aust Crit Care 2020;33(Suppl. 1):S40. DOI: 10.1016/j. aucc.2020.04.127.

20. Amorim FF, Silveira CDG, Santana RB, Moura EB, Silveira BTG, Silva $S F$, et al. Increased levels of reverse triiodothyronine and mortality in clinical critical ill patients. Intensive Care Med Exp 2019;7 (Suppl 3):00616. DOI: 10.1186/s40635-019-0265-y.

21. Wang F, Pan W, Wang H, Wang S, Pan S, Ge J. Relationship between thyroid function and ICU mortality: a prospective observation study. Crit Care 2012;16(1):R11. DOI: 10.1186/cc11151.

22. Wang YF, Heng JF, Yan J, Dong L. Relationship between disease severity and thyroid function in Chinese patients with euthyroid sick syndrome. Medicine (Baltimore) 2018;97(31):e11756. DOI: 10.1097/ MD.0000000000011756.
23. Casas F, Rochard P, Rodier A, Cassar-Malek I, Marchal-Victorion S, Wiesner RJ, et al. A variant form of the nuclear triiodothyronine receptor c-Erb A a1 plays a direct role in regulation of mitochondrial RNA synthesis. Mol Cell Biol 1999;19(12):7913-7924. DOI: 10.1128/ mcb.19.12.7913.

24. Legradi G, Lechan RM. The arcuate nucleus is the major source for neuropeptide $\mathrm{Y}$-innervation of thyrotropin-releasing hormone neurons in the hypothalamic paraventricular nucleus. Endocrinology 1998;139(7):3262-3670. DOI: 10.1210/endo.139.7.6113.

25. Mariotti S, Franceschi C, Cossarizza A, Pinchera A. The aging thyroid. Endocr Rev 1995;16(6):686-715. DOI: 10.1210/edrv-16-6-686.

26. Bianco AC, Salvatore D, Gereben B, Berry MJ, Larsen PR. Biochemistry, cellular and molecular biology, and physiological roles of the iodothyronine selenodeiodinases. Endocr Rev 2002;23(1):38-89. DOI: 10.1210/edrv.23.1.0455.

27. LoPresti JS, Eigen A, Kaptein E, Anderson KP, Spencer CA, Nicoloff JT. Alterations in 3,35-triiodothyronine metabolism in response to propylthiouracil, dexamethasone, and thyroxine administration in man. J Clin Invest 1989;84(5):1650-1656. DOI: 10.1172/JCl114343.

28. LoPresti JS, Gray D, Nicoloff JT. Influence of fasting and refeeding on 3,3,5-triiodothyronine metabolism in man. J Clin Endocrinol Metab 1991;72(1):130-136. DOI: 10.1210/jcem-72-1-130.

29. Davis P, Davis F. Acute cellular actions of thyroid hormone and myocardial function. Ann Thorac Surg 1993;56(1 Suppl.):S16-S23. DOI: 10.1016/0003-4975(93)90550-2.

30. Hak AE, Pols HA, Visser TJ, Drexhage HA, Hofman A, Witteman JC. Subclinical hypothyroidism is an independent risk factor for atherosclerosis and myocardial infarction in elderly women: the Rotterdam Study. Ann Intern Med 2000;132(4):270-278. DOI: 10.7326/0003-4819-132-4-200002150-00004.

31. Walsh JP, Bremner AP, Bulsara MK, O'Leary P, Leedman PJ, Feddema P, et al. Subclinical thyroid dysfunction as a risk factor for cardiovascular disease. Arch Intern Med 2005;165(21):2467-2472. DOI: 10.1001/ archinte.165.21.2467.

32. Parle JV, Maisonneuve P, Sheppard MC, Boyle P, Franklyn JA. Prediction of all-cause and cardiovascular mortality in elderly people from one low serum thyrotropin result: a 10-year cohort study. Lancet 2001;358(9285):861-865. DOI: 10.1016/S0140-6736(01)06067-6.

33. Cappola AR, Fried LP, Arnold AM, Danese MD, Kuller LH, Burke GL, et al. Thyroid status, cardiovascular risk, and mortality in older adults. JAMA 2006;295(9):1033-1041. DOI: 10.1001/jama.295.9.1033.

34. Sposito AC, Carvalho LS, Cintra RM, Araújo AL, Ono AH, Andrade JM, et al. Rebound inflammatory response during the acute phase of myocardial infarction after simvastatin withdrawal. Atherosclerosis 2009;207(1):191-194. DOI: 10.1016/j.atherosclerosis.2009.04.008.

35. Friberg L, Werner S, Eggertsen G, Ahnve S. Rapid down-regulation of thyroid hormones in acute myocardial infarction: is it cardioprotective in patients with angina? Arch Intern Med 2002;162(12):1388-1394. DOI: 10.1001/archinte.162.12.1388.

36. Zhang B, Peng W, Wang C, Li W, Xu Y. A low fT3 level as a prognostic marker in patients with acute myocardial infarctions. Intern Med 2012;51(21):3009-3015. DOI: 10.2169/internalmedicine.51.7902.

37. Kimur T, Kotajima N, Kanda T, Kuwabara A, Fukumura Y, Kobayashi I. Correlation of circulating interleukin-10 with thyroid hormone in acute myocardial infarction. Res Commun Mol Pathol Pharmacol 2001;110(1-2):53-58. https://pubmed.ncbi.nlm.nih.gov/12090356/

38. Peeters RP. Non thyroidal illness: to treat or not to treat? Ann Endocrinol 2007;68(4):224-228. DOI: 10.1016/j.ando.2007.06.011.

39. Peeters RP, Wouters PJ, Kaptein E, van Toor H, Visser TJ, van den Berghe G. Reduced activation and increased inactivation of thyroid hormone in tissues of critically ill patients. J Clin Endocrinol Metab 2003;88(7):3202-3211. DOI: 10.1210/jc.2002-022013.

40. Peeters RP, Kester MH, Wouters PJ, Kaptein E, van Toor H, Visser TJ, et al. Increased thyroxine sulfate levels in critically ill patients as a result of a decreased hepatic type I deiodinase activity. J Clin Endocrinol Metab 2005;90(12):6460-6465. DOI: 10.1210/jc.2005-0866. 
41. Peeters RP, van der Geyten S, Wouters PJ, Darras VM, van Toor H, Kaptein E, et al. Tissue thyroid hormone levels in critical illness: tissue thyroid hormone levels in critical illness. J Clin Endocrinol Metab 2005;90(12):6498-6507. DOI: 10.1210/jc.2005-1013.

42. Domingues JT, Cattani D, Cesconetto PA, Nascimento de Almeida BA, Pierozan P, Dos Santos K, et al. Reverse T3 interacts with av $\beta 3$ integrin receptor and restores enzyme activities in the hippocampus of hypothyroid developing rats: Insight on signaling mechanisms. Mol Cell Endocrinol 2018;470:281-294. DOI: 10.1016/j.mce.2017.11.013.
43. Zanatta AP, Zanatta L, Gonçalves R, Zamoner A, Silva FRMB. Rapid responses to reverse $T_{3}$ hormone in immature rat Sertoli cells: calcium uptake and exocytosis mediated by integrin. PLoS One 2013;8(10):e77176. DOI: 10.1371/journal.pone.0077176.

44. Farwell AP, Leonard JL. Nongenomic actions of thyroid hormone during fetal brain development. Curr Opin Endocrinol Metab 2005;12(1):17-22. DOI: 10.1097/01.med.0000152036.70617.1e. 